\title{
The lost parameter: adequacy of intraabdominal pressure monitoring
}

José Carlos Bonilla-Perez¹, Josep M Garcia-Alamino², Israel Alberto-Rodríguez¹, Joaquín Felipe-Vargas ${ }^{1}$, Juan Pablo González-Toledo1. 1) Intensive Care Unit. Hospital Universitario Ntra Sra de Candelaria, Tenerife, Spain. 2) Clinical Department Southern Europe. ConvaTec, Barcelona, Spain.

JoseMaria.GarciaAlamino@convatec.com

Background: Critically ill patients have an increased risk of developing intra-abdominal hypertension $(\mathrm{I} A \mathrm{H})$, either due to complicated admissions after surgery or due to associated risk factors during their stay in the intensive care unit. It has been shown in many studies that the prevalence of IAH in this population is increased (1). However, the monitoring of this parameter is still somewhat neglected (2).

Objectives: The objective of this study is to quantify the rate of monitoring of IAP (intra-abdominal pressure) in patients at risk for IAH.

Material and Methods: Prospective observational study in the period June-December 2016. This ICU have 26 symmetrical boxes. During this period, a review of the clinical records was made daily and box by box is the presence of risk factors for IAH was noted, according to the WSACS guidelines (the Abdominal Compartment Society). Apart from this proactive search, the doctor was consulted on the suitability of measuring the IAP in those patients who met the WSACS criteria when this parameter was not being monitored. The monitoring tool was the AbdoPressure® device (Figure 1).

Results: A total of 150 patients were included and the rate of IAP monitoring grouping all risk factors was only $17.3 \%$. For the different risk factors the monitoring rate rate was as follows: in case of a semi-recumbent position $15.8 \%$, acute respiratory failure $22.5 \%$, severe sepsis $33.3 \%$, polytrauma $40 \%$, presence of ascites $100 \%$ and abdominal surgery $100 \%$ (Figure 2).
Conclusions: Despite the high prevalence of IAH in the critically ill population, the growing evidence and recommendations for IAP monitoring and the increasing awareness of this problem in our unit we still observe a low overall IAP monitoring rate especially in some clear indications such as sepsis. These data has lead to specific actions to improve adherence to WSACS guidelines: joint sessions between surgeons and ICU physicians will be organized, as well as specific teaching sessions for nurses and allied health care personnel with regards to indications for and correct measurement of IAP.

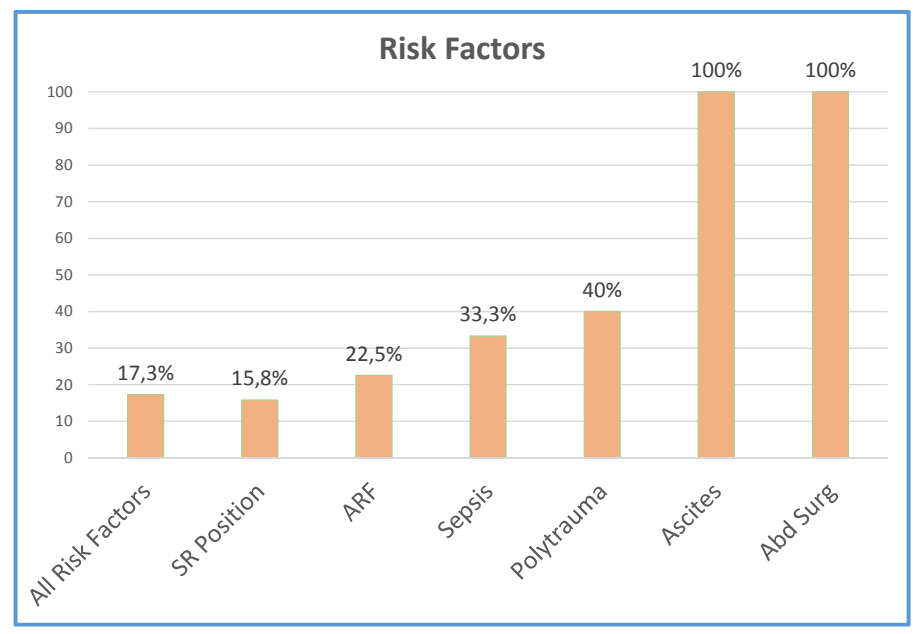

(Figure 1).
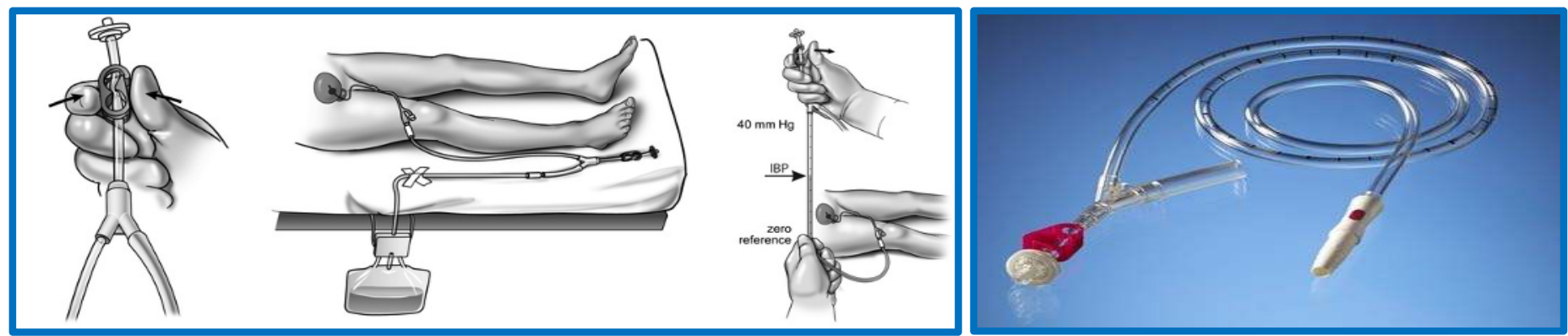

Extracted from Sugrue et al. (3)

1. Malbrain ML, Chiumello D, Cesana BM, Reintam-Blaser A, Starkopf J, Sugrue M, Pelosi P, Severgnini P, Hernandez G, Brienza N, Kirkpatrick AW, Schachtrupp A, Kempchen J, Estenssoro E, Vidal MG, De Laet I, De Keulenaer BL. A Systematic Review and individual patient data meta-analysis on intraabdominal hypertension in critically ill patients: The Wake-Up Project World Initiative on Abdominal Hypertension Epidemiology, a Unifying Project (WAKE-Up!). Minerva Anestesiol 2013. PubMed PMID: 24336093.

2. Malbrain ML, De Laet I, De Waele JJ, Sugrue M, Schachtrupp A, Duchesne J, Van Ramshorst G, De Keulenaer B, Kirkpatrick AW, Ahmadi-Noorbakhsh S, Mulier J, Pelosi P, Ivatury R, Pracca F, David M, Roberts DJ. The role of abdominal compliance, the neglected parameter in critically ill patients-a consensus review of 16 . Part 2: measurement techniques and management recommendations. Anaesthesiol Intensive Ther 2014; 46(5): 406-32.

3. Sugrue M, De Waele JJ, De Keulenaer BL, Roberts DJ, Malbrain ML. A user's guide to intra-abdominal pressure measurement. Anaesthesiol Intensive Ther. 2015;47(3):24151. 